\title{
Testicular oligometastasis from prostate cancer: Report of rare isolated recurrence after radiotherapy and intermittent androgen-deprivation therapy
}

\author{
Chan-Kyung J. Cho ${ }^{1,2}$; Samantha Sigurdson ${ }^{1}$; Christopher M. Davidson ${ }^{3}$; Michael Leveridge ${ }^{4}$; \\ Aamer Mahmud ${ }^{1,2}$ \\ ${ }^{1}$ Department of Oncology, Queen's University; ${ }^{2}$ Cancer Centre of Southeastern Ontario at Kingston General \\ Hospital; ${ }^{3}$ Department of Pathology and Molecular Medicine, Queen’s University, Kingston General \\ Hospital; ${ }^{4}$ Department of Urology, Queen’s University, Kingston General Hospital; Kingston, ON, Canada
}

Cite as: Can Urol Assoc J 2017 Dec 1; Epub ahead of print. http://dx.doi.org/10.5489/cuaj.4524

Published online December 1, 2017

\section{$* * *$}

\section{Abstract}

Testicular oligometastasis secondary to prostate cancer is rare. We present a case where a patient with locally advanced prostate cancer was treated with high-dose external beam radiotherapy and two years of androgen-deprivation therapy, followed by intermittent androgen suppression. Three and a half years after initial diagnosis, he was found to have a painless testicular mass. Orchiectomy was performed and histopathology demonstrated metastatic prostatic adenocarcinoma. He remains in clinical remission on intermittent androgen suppression eight years following initial treatment, and over four years after presentation with testicular metastasis.

\section{Case}

A 61-year-old Caucasian male presented to his family physician for urinary frequency and nocturia in 2008. He denied gross hematuria, dysuria, or any changes in stool or bowel function. Serum prostate-specific antigen (PSA) level was $20.3 \mathrm{ng} / \mathrm{mL}$, which led to a prostate biopsy. Histopathology showed adenocarcinoma with a Gleason score of $4+5$ (9/ 10) involving $80 \%$ of the tissue submitted. There was no extraprostatic, perineural, lymphatic, or vascular spread. A computed tomography (CT) scan of the abdomen and pelvis was performed for staging and showed left obturator lymphadenopathy, without evidence of distant metastasis. Excisional biopsy confirmed the presence of metastatic prostate carcinoma in this obturator node. On examination, he had a markedly enlarged prostate in keeping with a T3a lesion. Therefore, his prostate cancer was staged as T3a N1 M0.

He commenced androgen deprivation therapy (ADT) with an anti-androgen agent followed by luteinizing hormone-releasing hormone (LHRH) agonist in 2008, followed by a course of external beam radiation therapy delivered with a dose of 7000 cGy in 35 fractions. His PSA nadir in 2009 was $0.1 \mathrm{ng} / \mathrm{mL}$. After 2 years of ADT, he opted for intermittent androgen 
suppression and his LHRH injections were stopped. He remained clinically well until a follow up visit in July 2012, when he was found to have a painless testicular mass associated with vague paresthesia not corresponding to a specific dermatomal distribution. He denied any other neurologic, urinary, or constitutional symptoms. At the time, he had been off ADT for 18 months, and his PSA was $2.8 \mathrm{ng} / \mathrm{mL}$. Scrotal ultrasound revealed the presence of tumour concerning for malignancy [Figure 1], and he underwent a left radical orchiectomy in August 2012. Pathologic examination revealed five nodules of metastatic adenocarcinoma (the largest measuring $4 \mathrm{~mm}$ ) that involved the testicular hilum and epididymis [Figures 2-4]. The tumour possessed the morphologic and immunohistochemical features (positive for PSA and prostatic acid phosphatase, and negative for CK7, CK20, CD117, PLAP, AFP, CD30, and inhibin) of prostatic adenocarcinoma. CT scan of the abdomen and pelvis and a bone scan were negative for other metastatic disease. His post-operative PSA was $0.1 \mathrm{ng} / \mathrm{mL}$; however it slowly rose to $12.7 \mathrm{ng} / \mathrm{mL}$ in February 2015. He recommenced ADT, and stopped in January 2016 when his PSA became undetectable. His recent PSA from October 2016 was $0.3 \mathrm{ng} / \mathrm{mL}$ and he remains asymptomatic.

\section{Discussion}

Adenocarcinoma of the prostate is one of the most common cancers among men, though testicular metastasis is rare with a reported incidence of $0.5 \%$ among an autopsy cohort. ${ }^{1}$ The most likely sources of testicular metastasis, excluding hematologic malignancies, are cancers of the prostate, lung, melanoma, and kidney. ${ }^{2}$ There have been less than 200 reported incidences of testicular metastasis from prostate cancer, and the majority of these cases described in the literature have been incidental findings at autopsy or after bilateral orchiectomy performed for androgen suppression, most often presenting with other distant metastases concurrently. 1,3,4

The three most commonly used treatment modalities for prostate cancer are ADT, radiation therapy, and prostatectomy. ADT has been used to treat prostate cancer since the 1940s, and its application has been continuously optimized to minimize adverse effects while maintaining therapeutic benefits. Intermittent androgen suppression was introduced in the 1980s as a means to reduce morbidity, but there remained controversy over the effectiveness of intermittent ADT (IADT) versus continuous ADT (CADT). ${ }^{5}$ In the last few years a large-scale clinical trial, NCIC PR.7, and a systemic review independently concluded that IADT is comparable to continuous therapy with respect to overall survival but with better quality of life. ${ }^{6,7}$ It is therefore possible that the risk and incidence of rare metastatic disease may be similar in patients who receive IADT compared to those with CADT. On the other hand, the likelihood of an increase in developing regional or distant metastasis during a break of IADT for hormonesensitive prostate cancer remains unknown. Greater sample size and data collection may help to adequately answer this question. We recommend IADT when PSA is equal to or over $10 \mathrm{ng} / \mathrm{mL}$, provided PSA kinetics are favourable and there is no clinical evidence of disease progression. The same criteria are used for recommencement of ADT.

The prognosis of testicular metastasis from prostate cancer is poorly understood, especially for the cases of solitary testicular oligometastasis, due to extremely small sample size. 
Most previous reports of testicular metastasis involved patients who had other distant metastasis, bone being the most common site. For example, one case report described a patient who presented with bone metastases and was treated with ADT, and then developed testicular swelling and was found to have a testicular metastasis. ${ }^{4}$ Although there is a large range varying from 5 to 78 months of reported survival for these cases, metastasis to the testis has been commonly accepted as a sign of advanced disease since they tend to be accompanied by metastasis to other organs. $3,4,10$

This case, however, is an illustration of oligometastatic disease that may be amenable to standard treatments despite the presence of distant metastasis. The oligometastatic state is defined as metastatic cancer limited in number and organ sites that may indicate a more indolent biology and progression, and one review of retrospective studies defined oligometastatic prostate cancer as including up to five sites of extrapelvic lesions. ${ }^{11}$ Aggressive metastasis-directed therapies for oligometastasis have been used for over a decade for malignancies such as nonsmall cell lung cancer, renal cell cancer, and colorectal cancer. There have been studies that suggest hormone-sensitive prostate cancer with oligometastasis may well be eligible for a similar approach given the remarkably favourable prognosis observed in men with oligometastasis. ${ }^{12,13}$ Recently, a possible survival benefit of local therapy combined with ADT in metastatic patients has emerged. ${ }^{14}$ Two review studies suggested that local or metastatic-directed radiotherapy are reasonable interventions as toxicity is minimal and decreases the necessity for subsequent palliative treatments. ${ }^{11,15}$ Although most data on oligometastatic prostate cancer is retrospective, there are ongoing clinical trials investigating the role of different treatment options, both separately and as multimodality therapy, in patients with oligometastatic hormone-sensitive prostate cancer. ${ }^{15}$ 


\section{References}

1. Bubendorf L, Schopfer A, Wagner U, et al. Metastatic patterns of prostate cancer: an autopsy study of 1,589 patients. Hum pathol 2000;31:578-83.

2. Schneider A, Kollias A, Woziwodzki J, et al. Testicular metastasis of a metachronous small cell neuroendocrinic prostate cancer after anti-hormonal therapy of a prostatic adenocarcinoma. Case report and literature review [abstract]. Urologe A 2006;45:75-80.

3. Tu SM, Reyes A, Maa A, et al. Prostate carcinoma with testicular or penile metastases. Cancer 2002;94:2610-7.

4. Kusaka A, Koie T, Yamamoto H, et al. Testicular metastasis of prostate cancer: a case report. Case Rep Oncol 2014;7:643-7.

5. Buchan NC, Goldenberg SL. Intermittent androgen suppression for prostate cancer. Nat Rev Urol 2010;7:552-60.

6. Crook JM, O'Callaghan CJ, Duncan G, et al. Intermittent androgen suppression for rising PSA level after radiotherapy. N Engl J Med 2012;367:895-903.

7. Abrahamsson PA. Potential benefits of intermittent androgen suppression therapy in the treatment of prostate cancer: a systematic review of the literature. Eur Urol 2010;57:4959.

8. Pound CR, Partin AW, Eisenberger MA, et al. Natural history of progression after PSA elevation following radical prostatectomy. JAMA 1999;281:1591-7.

9. Hussain M, Tangen CM, Berry DL, et al. Intermittent versus continuous androgen deprivation in prostate cancer. N Engl J Med 2013;368:1314-25

10. Korkes F, Gasperini R, Korkes KL, et al. Testicular metastases: a poor prognostic factor in patients with advanced prostate cancer. World J Urol 2009;27:113-5.

11. Tosoian JJ, Gorin MA, Ross AE, Pienta, et al. Oligometastatic prostate cancer: definitions, clinical outcomes, and treatment considerations. Nat Rev Urol 2017;14:15-25.

12. Schweizer MT, Zhou XC, Wang H, et al. Metastasis-free survival is associated with overall survival in men with PSA-recurrent prostate cancer treated with deferred androgen deprivation therapy. Ann Oncol 2013;24:2881-6.

13. Ost P, Decaestecker K, Lambert B, et al. Prognostic factors influencing prostate cancerspecific survival in non-castrate patients with metastatic prostate cancer. Prostate 2014;74:297-305.

14. Rusthoven CG, Jones BL, Flaig TW, et al. Improved survival with prostate radiation in addition to androgen deprivation therapy for men with newly diagnosed metastatic prostate cancer. J Clin Oncol 2016;34:2835-42.

15. Clement JM, Sweeney CJ. Evolving treatment of oligometastatic hormone-sensitive prostate cancer. J Oncol Pract 2017;13:9-18. 


\section{Figures and Tables}

Fig. 1.

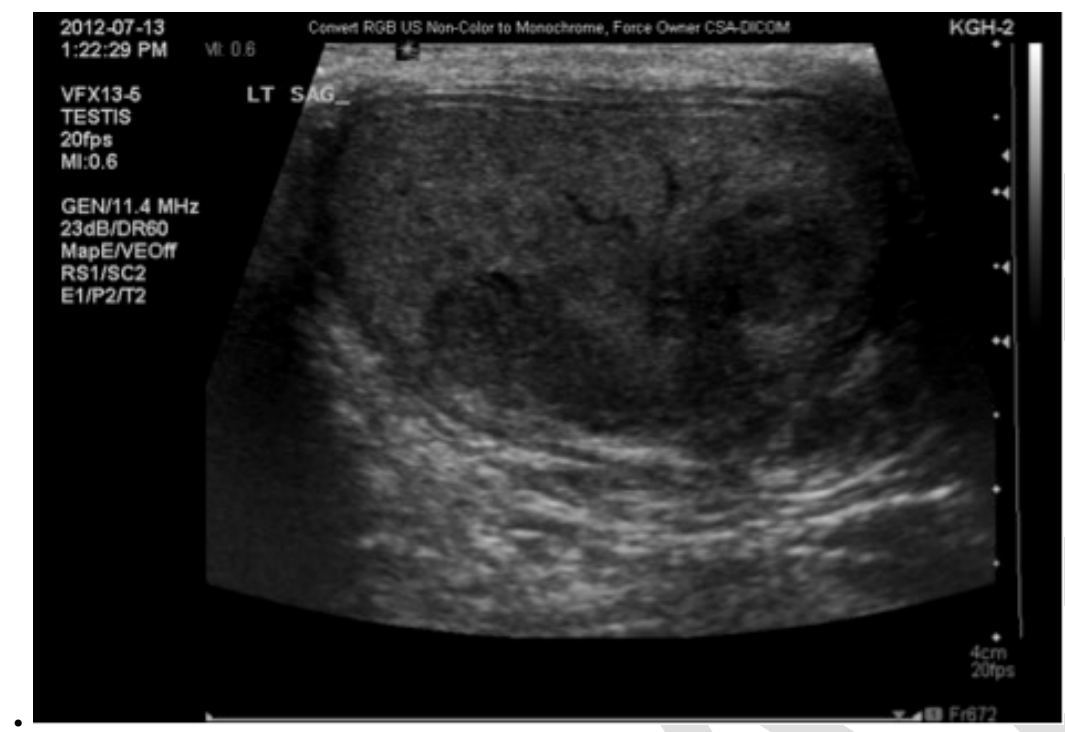

Fig. 2.

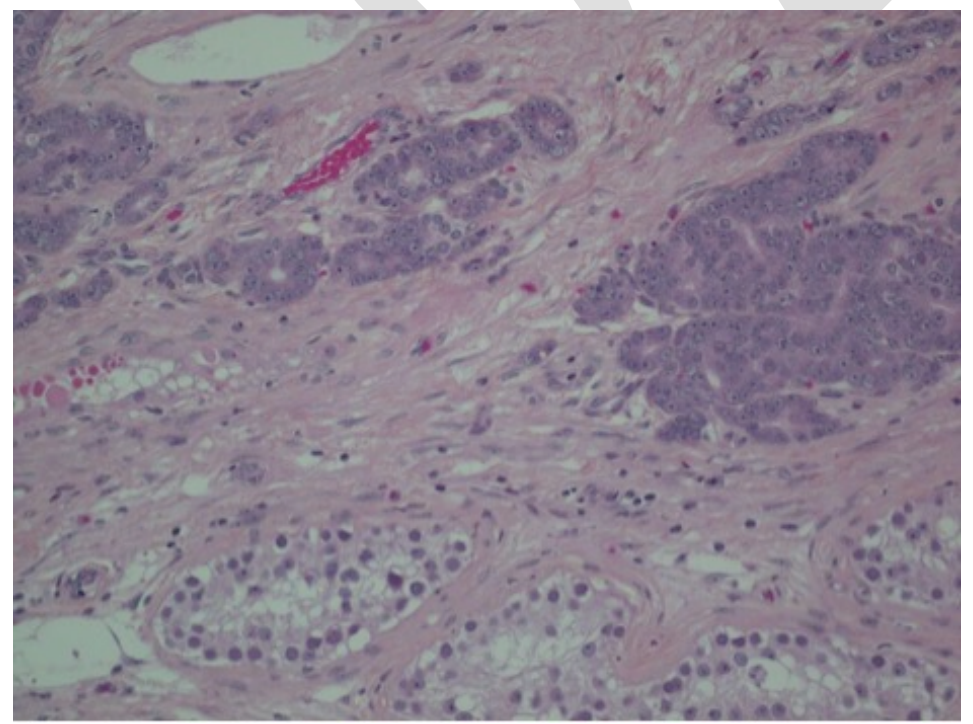


Fig. 3.

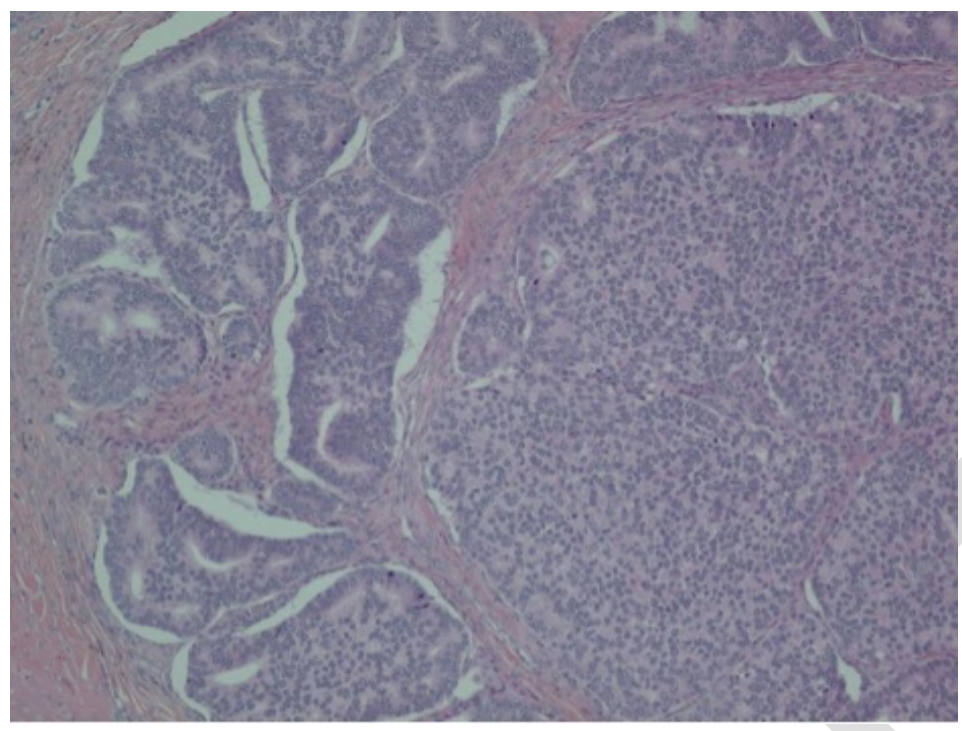

Fig. 4.

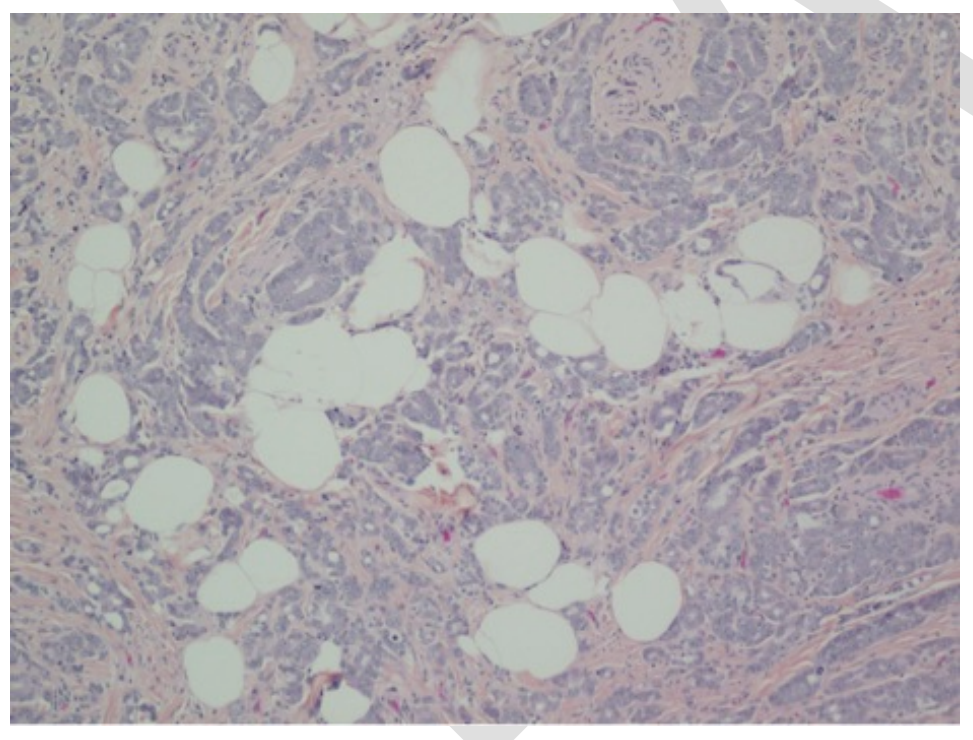

